\title{
Gender Sensitivity and Gender Equality Consciousness of Dental Hygiene Students
}

\author{
Hee-Jung Lim', Ki-Eun Kim², and Eun-Jung NamKoong ${ }^{3, \dagger}$ \\ ${ }^{1}$ Department of Dental Hygiene, College of Health Science, Eulji University, Seongnam 13135, ${ }^{2}$ Department of \\ Dental Hygiene, Daejeon Institute of Science and Technology, Daejeon 35408, ${ }^{3}$ Department of Dental Hygiene, \\ Catholic Kwandong University, Gangneung 25601, Korea
}

\begin{abstract}
Background: This study was conducted to identify the level of gender sensitivity and gender equality consciousness among dental hygiene students and to confirm the necessity of gender equality programs in the curriculum.

Methods: A self-report questionnaire was conducted with some dental hygiene students using the Gender Sensitivity tool and Korean Gender Egalitarianism Scale for Adolescents (KGES-A).

Results: First, the gender equality consciousness of the students who took women's studies was high in the areas of educational life and socio-cultural life, and that of the subjects of grandparent families and Catholic was found to be high in the domestic life area. Second, the gender sensitivity of the subjects who took women's studies was found to be high in all sub-areas. In addition, the gender sensitivity of females was higher in the areas of sexual identity, non-violence, and self-reflection than that of males. That of 4-year college students was higher in the areas of sexual identity, openness to gender roles, and non-violence than that of 3-year college students. In addition, the gender sensitivity of Catholic students was high in the areas of sexual identity and openness to gender roles. Third, gender equality consciousness was found to have an effect depending on whether subjects took women's studies, family type, family type, and religion, and gender sensitivity was found to have an effect depending on whether subjects took women's studies or gender.

Conclusion: Since dental hygienist is a profession that targets humans, education that can instill equal awareness and values of humans is important. To inspire gender sensitivity and gender equality consciousness in a prospective professional, it is necessary to conduct programs and education related to gender intelligence within dental hygiene curriculum.
\end{abstract}

Key Words: Gender equality, Gender sensitivity, Students

\section{Introduction}

The digital information society, which is used as a concept in contrast to the industrial, the agricultural, and the hunting society demands women's social participation and needs by emphasizing the creation of values through mental labor as one of the features of modern society. Due to changes in modern society, cooperation between men and women, rather than fixed gender role, is emerging as the subject of the times and is acting as a key engine for social development.
In consideration of the social situation, Korean society has devised various systems aimed at gender equality to overcome structural gender discrimination, which is patriarchal and gender-specific, and has attempted to make changes. Since 2008, Korea's gender statistic indicators have been published every year, and the Basic Act on Women's Development in 2014 was revised to the Basic Act on Gender Equality and has been in effect since July $1,2015^{1)}$. In addition, to successfully implement the policy to raise gender awareness, it has conducted gender impact assessments for central administrative agencies and 
metropolitan regional governments since 20052). The target has been expanded to public officials of basic autonomous organizations and metropolitan and provincial offices of education.

In accordance with the social atmosphere in which gender consciousness and gender equality consciousness affect the way of life of members of society, it should not remain at the policy level; recently, the concepts of gender sensitivity and gender equality have emerged to improve perceptions related to gender and to promote the establishment of gender role values ${ }^{3)}$.

Gender sensitivity is the ability to detect gender issues and recognize the problems arising from gender discrimination and the effects of those differences ${ }^{3)}$, taking the existence of social, cultural, economic, and political inequalities that may exist between men and women into account, and meaning the degree to which they are sensitive. In addition, gender equality means that men and women are treated equally regardless of gender by breaking down the concept of confrontation between genders ${ }^{4}$. In other words, equal status and opportunities should be guaranteed when participating in social activities, whether women or men, and it implies that they do not have stereotypes about gender attributes ${ }^{5)}$.

From this viewpoint, it can be said that having appropriate gender sensitivity and gender equality is important not only for individual self-realization, but also for social development ${ }^{6}$.

However, even though students in the Department of Dental Hygiene are preliminary professionals who have to establish a cooperative relationship regardless of gender in the workplace as dental hygienists after graduation, there is concern that they may not be able to escape from the traditional gender roles and stereotypes by living with women during most of their school life. Examining previous studies ${ }^{6-9)}$, it was confirmed that studies on gender sensitivity and gender equality were limited to specific occupational groups.

Accordingly, we examine the gender sensitivity and gender equality consciousness of students in the Department of Dental Hygiene as prospective professionals who will meet various targets and co-workers, and we assess the need for programs to promote such aspects among dental hygiene students in the curriculum.

\section{Materials and Methods}

\section{Participants}

This study was conducted from March 20 to 30, 2021 using an in-person self-report questionnaire for dental hygiene students at three universities in Daejeon, Gangwon and Gyeonggi. The subject sample size was derived from Cohen's power analysis using $\mathrm{G}^{*}$ power 3.1 .9 , and the minimum sample size required was 200 persons under conditions of significance level 5\% (both sides), statistical power $80 \%$, and effect size of 0.15 , but an additional 200 persons were examined considering the dropout rate. The purpose of this study and the contents of confidentiality were explained, and a total of 412 subjects were finalized, excluding those that did not agree to participate and whose responses were not faithful. All Participants gave written informed consent.

This study was approved by Institutional Review Board at Daejeon Institute of Science and Technology.

\section{Instrument}

\section{1) Gender sensitivity}

A tool developed by Lee ${ }^{3)}$ was used to measure gender sensitivity. The survey consisted of 31 questions, including nine for openness to gender roles, seven for non-violence, seven for gender identity, and eight for self-reflection. A total of 19 questions (numbers 1 to $5,8,9,11,12,17$ to 25 , 31) were inverse questions, and the higher the score on a 5-point scale, the higher the perception of gender sensitivity. In terms of reliability the Cronbach's alpha of this study was found to be 0.959 , indicating good reliability.

\section{2) Gender equality consciousness}

To measure gender equality consciousness, the Korean Gender Egalitarianism Scale for Adolescents (KGES-A) ${ }^{10)}$ by the Korean Women's Development Institute (2003) was used. A total of 60 questions consisted of 15 questions on family life, 15 on school life, 15 on professional life, and 15 on social and cultural life. Questions \#1-6, \#8-20, \#22, \#24-33, \#35-36, \#38, \#42, \#44-45, \#47, \#49-52, \#55-60 
are reverse questions. The higher the score on a 5-point scale, the higher the awareness of gender equality. In terms of reliability, Cronbach's alpha was found to be 0.858 .

\section{Analysis}

Using the IBM SPSS/WIN 20.0 (IBM Corp., Armonk, NY, USA) program, the general characteristics of the subjects were frequency and percentage, and the difference in the subjects' general characteristics and gender sensitivity, and gender equality consciousness t-test and ANOVA were conducted. Verification was conducted using the Scheffe test. Multiple regression analysis was performed to examine the factors affecting gender sensitivity and gender equality consciousness.

\section{Results}

\section{General characteristics of study subjects}

The results of examining the general characteristics of the study subjects are reported in Table 1 . In terms of gender, 389 were female (94.4\%), 330 (80.1\%) were among 19 to 22 years old, and $250(60.7 \%)$ were four-year university students. First and third graders accounted for $144(35.0 \%)$, and the second grade was $124(30.1 \%)$. As for family type, 241 (58.5\%) were from nuclear families, 124 (30.1\%) extended families, 223 (54.1\%) were siblings, among these 141 were sisters (34.2\%). A total of $282(68.4 \%)$ indicated they did not follow any religion, 87 $(21.1 \%)$ were Christian, and 44 (10.7\%) subjects were taking women's studies.

\section{Difference of gender sensitivity according to general characteristics}

The results of examining the differences in gender sensitivity according to the general characteristics of the study subjects are reported in Table 2. Females were higher in terms of gender identity, non-violence, and self-reflection $(p<0.05)$, and 4-year-college students were higher in gender identity, openness to gender roles, and non-violence than 3 -year-college students $(\mathrm{p}<0.05)$. The subjects who took women's studies were high in all sub-variables $(\mathrm{p}<0.05)$. As for religion, Catholic subjects was high in openness to gender identity and gender roles $(\mathrm{p}<0.01)$

\section{Difference of gender equality consciousness according to general characteristics}

The differences in gender equality consciousness according to the general characteristics of the study subjects are presented in Table 3. The subjects who took women's studies were higher in educational life and social and cultural life $(\mathrm{p}<0.05)$, while the family type with grandparents $(p<0.05)$ and Catholics $(p<0.01)$ were the highest.

\section{Influence of general characteristics on gender equality consciousness and gender sensitivity}

The results of examining the effects of the general characteristics of the study subjects on gender equality consciousness and gender sensitivity are reported in Table 4. Gender equality consciousness was found to be affected by taking women's studies $(\beta=-2.339, \mathrm{p}<0.05)$, nuclear

Table 1. General Characteristics of the Study Subjects $(n=412)$

\begin{tabular}{llc}
\hline & Category & $\mathrm{n}(\%)$ \\
\hline Gender & Female & $389(94.4)$ \\
Age (y) & Male & $23(5.6)$ \\
\multirow{2}{*}{ School system } & $19 \sim 22$ & $330(80.1)$ \\
& 23 & $82(19.9)$ \\
Grade & 3 -year system & $162(39.3)$ \\
& 4-year system & $250(60.7)$ \\
& Freshman & $144(35.0)$ \\
Family type & Sophomore & $124(30.1)$ \\
& Junior & $144(35.0)$ \\
& Extended family & $124(30.1)$ \\
& Nuclear family & $241(58.5)$ \\
& Single parent family & $40(9.7)$ \\
Family composition & Grandparent family & $3(0.7)$ \\
& Etc. & $4(1.0)$ \\
& Only daughter/son & $38(9.2)$ \\
& Siblings & $223(54.1)$ \\
& Sisters & $141(34.2)$ \\
& Brother & $10(2.4)$ \\
Religion & Catholicism & $20(4.9)$ \\
& Christian & $87(21.1)$ \\
& Buddhism & $23(5.6)$ \\
Women's studies course & No religion & $282(68.4)$ \\
& Yes & $44(10.7)$ \\
& No & $368(89.3)$ \\
\hline
\end{tabular}


Table 2. Difference of Gender Sensitivity according to General Characteristics

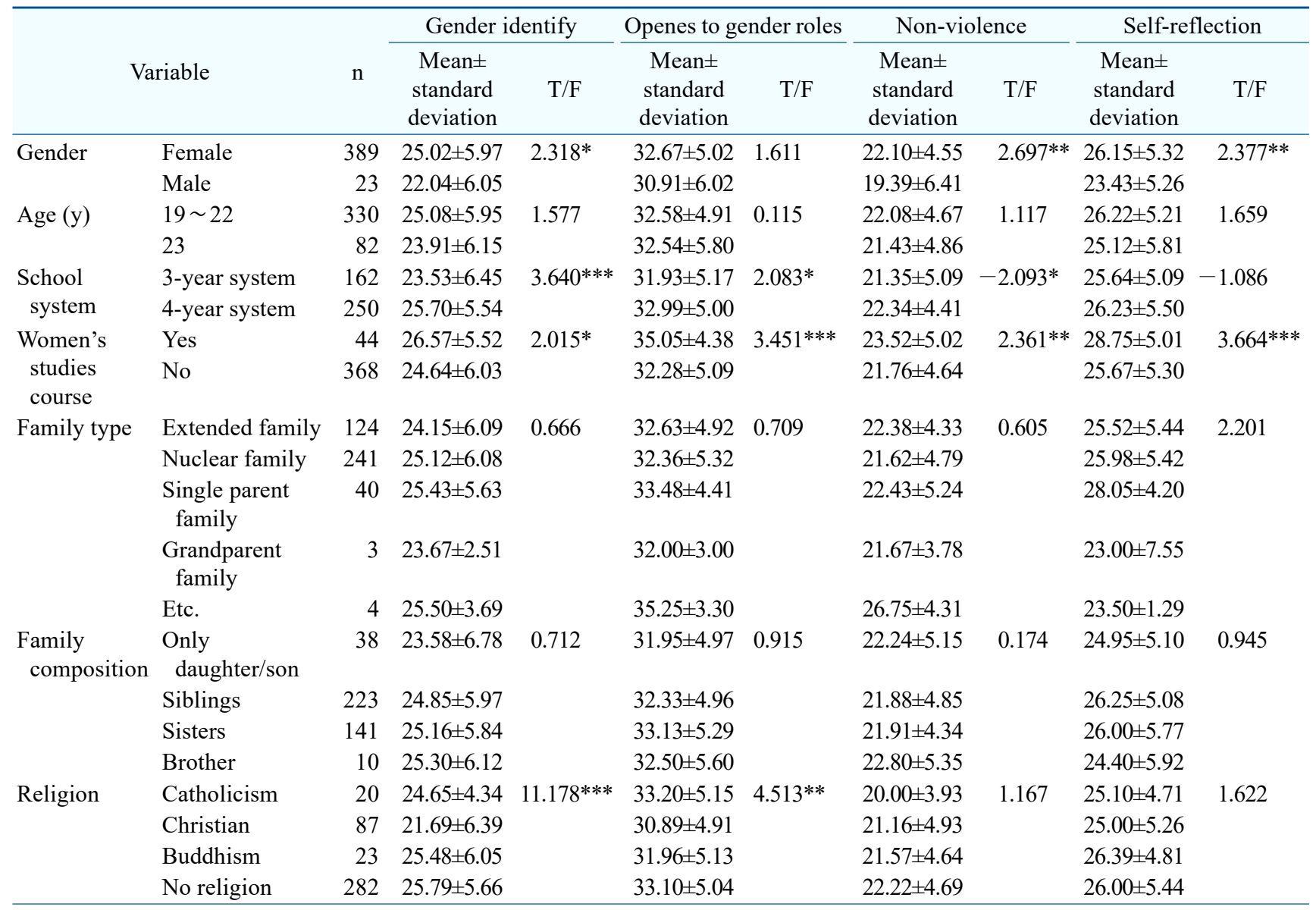

By t-test or one-way ANOVA.

Post hoc test was conducted from Scheffe test.

${ }^{*} \mathrm{p}<0.05, * * \mathrm{p}<0.01,{ }^{* * *} \mathrm{p}<0.001$ by multiple regression analysis.

family $(\beta=2.218, \mathrm{p}<0.05)$, and Christian $(\beta=-2.239, \mathrm{p}<$ $0.05)$, with an R-squared value of 0.065 . Gender sensitivity was found to be influenced as follows: male $(\beta=-3.751, p<0.001)$, 4-year college program $(\beta=3.502$, $\mathrm{p}<0.01)$, taking women's studies $(\beta=-4.196, \mathrm{p}<0.001)$, and the R-squared value was 0.169 .

\section{Discussion}

In modern society, various issues continue to emerge. Among them, the issue of gender has been an ongoing hot topic. Over the past few decades, Korean society has made various institutional efforts for gender equality ${ }^{1,2)}$. Nevertheless, the persistent gender stereotypes of individuals still influence the perception and way of life of the entire society. In this regard, gender sensitivity has emerged as the concept for the spread of practical gender equality. Gender sensitivity is the ability to sensitively recognize gender differences and inequalities, and the effects of those differences, and to demonstrate willingness to improve gender discrimination ${ }^{11)}$. Gender equality consciousness refers to awareness of gender discrimination based on traditional gender roles ${ }^{12)}$.

Because dental hygienist is a job that targets humans, equal recognition of humans is necessary. From this viewpoint, this study sought to understand the gender sensitivity and gender equality consciousness of dental hygiene students. In addition, the purpose of this study was to determine whether there is a need to provide a gender equality program in the curriculum by measuring 
Hee-Jung Lim, et al. : Gender Sensitivity and Gender Equality Consciousness of Dental Hygiene Students

Table 3. Difference of Gender Equality Consciousness according to General Characteristics

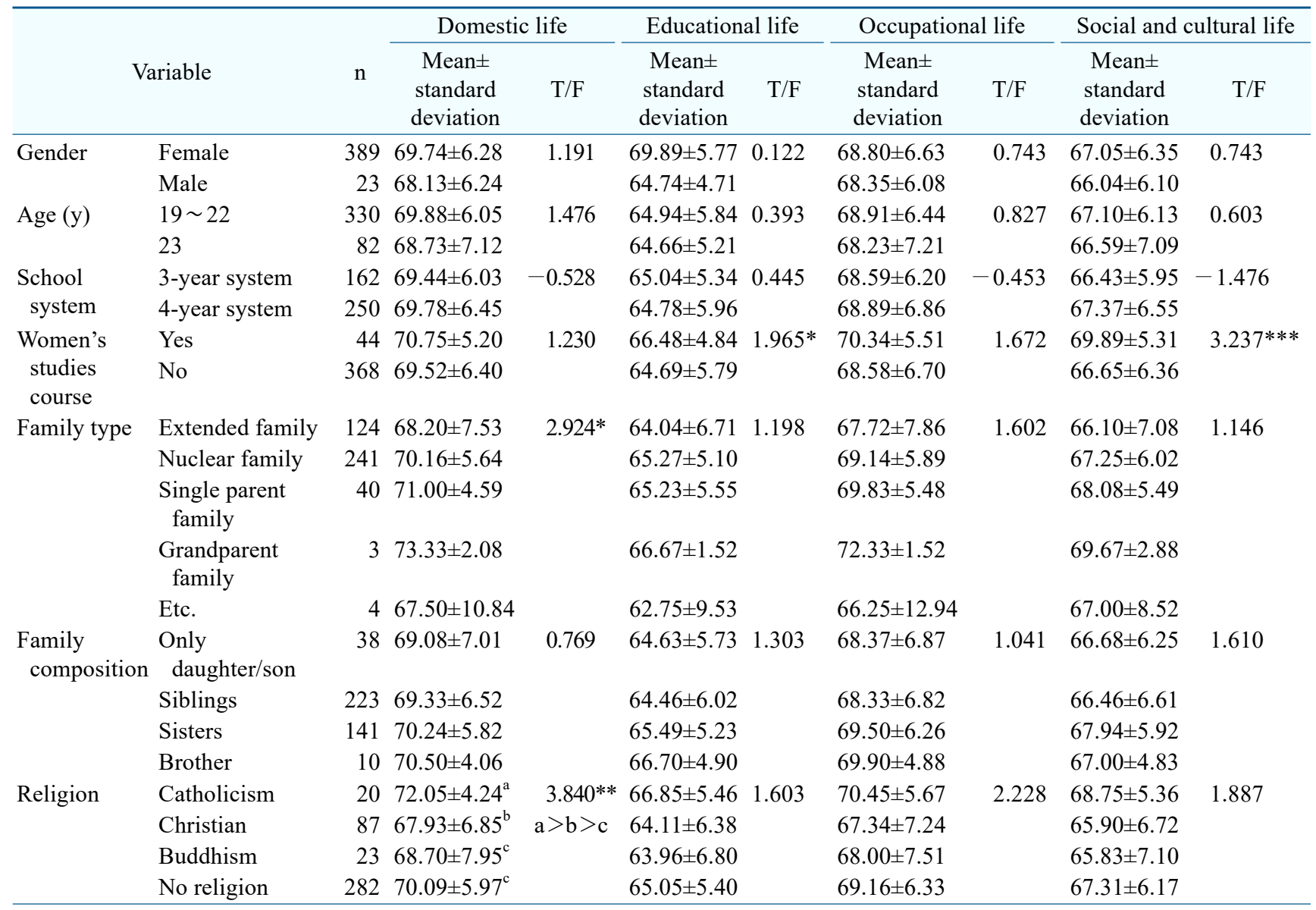

By t-test or one-way ANOVA.

${ }_{\mathrm{a}, \mathrm{b}, \mathrm{c}}$ Post hoc test was conducted from Scheffe test.

$* \mathrm{p}<0.05, * * \mathrm{p}<0.01, * * * \mathrm{p}<0.001$ by multiple regression analysis.

the level of gender sensitivity and gender equality consciousness of dental hygiene students as prospective professionals. The results reveal that women's gender sensitivity was higher than that of men in the areas of sexual identity, non-violence, and self-reflection. This is similar to the results of previous studies ${ }^{9,13)}$ showing significant differences in gender sensitivity by gender. Furthermore, in health sectors with a large number of female students, the sense of equality was reported to be higher than that of other departments ${ }^{14)}$. In addition, the gender sensitivity of 4-year-college students was found to be higher than that of 3-year-college students in the areas of gender identity, openness to gender roles, and non-violence. It is inferred that, in addition to their professional knowledge, 4-year-college students are exposed to various liberal arts subjects related to personal literacy and consciousness ${ }^{15)}$ and have more experience than 3-year-college students, which may lead to differences in gender sensitivity depending on the school system. This is also linked to reports in previous studies that gender sensitivity changes due to the influence of various activities after entering university ${ }^{8}$. These results suggest that there is a possibility that gender sensitivity may change sufficiently through youth, and the spread of an atmosphere of gender equality in universities and the role of educators can be important for this.

In particular, the subjects who took women's studies had higher gender sensitivity in all areas than those who did not. Gender equality consciousness was also higher in the areas of educational life and social and cultural life of 
Table 4. Influence of General Characteristics on Gender Sensitivity and Gender Equality Consciousness

\begin{tabular}{|c|c|c|c|c|c|c|}
\hline \multirow{2}{*}{ Variable } & \multicolumn{3}{|c|}{ Gender sensitivity } & \multicolumn{3}{|c|}{ Gender equality consciousness } \\
\hline & $\mathrm{B}$ & $\beta$ & $\mathrm{t}$ & B & $\beta$ & $\mathrm{t}$ \\
\hline (constant) & 107.666 & & 22.682 & 282.559 & & 35.805 \\
\hline \multicolumn{7}{|l|}{ Gender (ref_female) } \\
\hline Male & -11.877 & -0.181 & $-3.751 * * *$ & -5.665 & -0.055 & -1.076 \\
\hline \multicolumn{7}{|l|}{ Age (ref_19 22) } \\
\hline$\leq 23$ & -1.053 & -0.028 & -0.521 & -1.320 & -0.022 & -0.393 \\
\hline \multicolumn{7}{|c|}{ School system (ref_3-year system) } \\
\hline 4-year system & 4.424 & 0.144 & $3.052 * *$ & 0.142 & 0.003 & 0.059 \\
\hline \multicolumn{7}{|c|}{ Women's studies course (ref_yes) } \\
\hline No & -9.540 & -0.196 & $-4.196 * * *$ & -8.843 & -0.116 & $-2.339 *$ \\
\hline \multicolumn{7}{|c|}{ Family type (ref_Extended family) } \\
\hline Nuclear family & 0.373 & 0.012 & 0.238 & 5.771 & 0.121 & $2.218^{*}$ \\
\hline Single parent family & 3.075 & 0.061 & 1.185 & 7.202 & 0.091 & 1.670 \\
\hline Grandparent family & 0.922 & 0.005 & 0.111 & 20.057 & 0.072 & 1.458 \\
\hline Etc. & 3.705 & 0.024 & 0.511 & -6.263 & -0.026 & -0.520 \\
\hline \multicolumn{7}{|c|}{ Family composition (ref_only daughter/son) } \\
\hline Siblings & 2.364 & 0.078 & 0.894 & -0.185 & -0.004 & -0.045 \\
\hline Sisters & 3.245 & 0.102 & 1.178 & 4.400 & 0.089 & 1.022 \\
\hline Brother & 2.447 & 0.025 & 0.457 & 5.337 & 0.035 & 0.637 \\
\hline \multicolumn{7}{|l|}{ Religion (ref_Catholicism) } \\
\hline Christian & -5.048 & -0.137 & -1.433 & -13.113 & -0.227 & $-2.239 *$ \\
\hline Buddhism & 0.596 & 0.009 & 0.137 & -11.606 & -0.113 & -1.603 \\
\hline No religion & 3.755 & 0.116 & 1.136 & -6.433 & -0.127 & -1.171 \\
\hline $\mathrm{F}(\mathrm{p})$ & & $5.004 * * *$ & & & $1.707^{*}$ & \\
\hline Adjusted $\mathrm{R}^{2}$ & & 0.169 & & & 0.065 & \\
\hline
\end{tabular}

${ }^{*} \mathrm{p}<0.05,{ }^{*} \mathrm{p}<0.01, * * * \mathrm{p}<0.001$ by multiple regression analysis.

students who participated in the women's studies course. This reaffirmed that education plays an important role in promoting gender equality ${ }^{16-18)}$. In addition, differences in gender equality consciousness according to family type and religion were also confirmed. Specifically, grandparent families and Catholics showed high gender equality consciousness in the area of domestic life. This is classified into the content of traditional gender roles in Korean society as questions related to the housework of men and women, attitudes toward the authority and relationship between parents or couples, and how to raise children. In previous studies, subjects with a nuclear family had the highest gender equality consciousness ${ }^{19)}$, which was different from the results of the current study. Through detailed analysis of gender sensitivity and gender equality consciousness for each sub-area, follow-up research on the differences from the results of the previous studies seems to be necessary.
When the results of the current study were combined, it is particularly noteworthy that gender equality consciousness and gender sensitivity were found to be high in those who participated in gender-sensitive education, such as women's studies. This is consistent with the fact that in previous studies, students who have participated in courses related to gender roles had a significant influence on their gender equality consciousness ${ }^{6}$. Therefore, to inspire gender sensitivity and gender equality consciousness to a prospective professional, it is necessary to implement gender consciousness-related programs and gender equality education in the curriculum of dental hygiene students. In addition, it is necessary to establish a gender-equal culture within the school and to make active connections with educational programs. From the results, it was confirmed that taking women's studies, family type, and religion influence the gender equality consciousness of dental hygiene department students. Therefore, when 
implementing a gender-sensitive program, the educational content should be structured by carefully considering background factors such as gender, school system, family type, and religion of the students in the Department of Dental Hygiene.

Dental hygienist is a profession that targets humans. For this reason, education that can instill equal awareness and values of human beings is important. Based on the results of this study, education on the value of gender equality should be provided.

Since this study was limited to some dental hygiene students, there is a limitation in the generalization of the research results. In the future, it is necessary to expand the survey sample to carry out follow-up research and to supplement the research results through an in-depth analysis of related factors Despite some limitations, to the best of the author's knowledge, this study is the first in Korea to identify the gender sensitivity and gender equality consciousness of dental hygiene students, and it is significant in it served as an opportunity to newly recognize the practical necessity for gender-aware education in the dental hygiene curriculum. This suggests that it will be a useful starting point for promoting the development of the gender cognitive curriculum in the training process for dental hygienists.

\section{Notes}

\section{Conflict of interest}

No potential conflict of interest relevant to this article was reported.

\section{Ethical approval}

This study was approved by the institutional review board of Daejeon Institute of Science and Technology (IRB No. 1044342-20210506-HR-009-03).

\section{Author contributions}

Conceptualization: Hee-Jung Lim, Ki-Eun Kim, and Eun-Jung NamKoong, Data acquisition: Hee-Jung Lim, Ki-Eun Kim, and Eun-Jung NamKoong. Formal analysis: Hee-Jung Lim. Funding: Hee-Jung Lim, Ki-Eun Kim, and Eun-Jung NamKoong. Supervision: Hee-Jung Lim,
Ki-Eun Kim, and Eun-Jung NamKoong. Writing-original draft: Hee-Jung Lim, Ki-Eun Kim, and Eun-Jung NamKoong. Writing-review \& editing: Eun-Jung NamKoong.

\section{ORCID}

Hee-Jung Lim, https://orcid.org/0000-0002-4738-3032

Ki-Eun Kim, https://orcid.org/0000-0002-5989-9503

Eun-Jung NamKoong, https://orcid.org/0000-0001-7108-8175

\section{References}

1. Joo JS, Song CS, Park GP: Gender statistics in Korea 2016. Korean Women's Development Institute, Seoul, pp.1-617, 2017.

2. Kim KJ: A study of gender-perspective policy recognition in local government. KJLGAS 27: 1-23, 2013. https://doi.org/10.18398/kjlgas.2013.27.3.1

3. Retrieved April 2, 2021, from https://www.kigepe.or.kr/ user/cop/bbs/selectBoardList.do?bbsId=BBSMSTR_000000 $000050 \&$ menuNo $=14100$

4. McHugh MC, Frieze IH: The measurement of gender-role attitudes: a review and commentary. Psychol Women Q 21: 1-16, 1997. https://doi.org/10.1111/j.1471-6402.1997.tb00097.x

5. Koo HK, Lee HY, Jin YE: A study for the military organizational culture and consciousness of gender equality. KAMW 9: 115-146, 2016.

6. Chung MR: A study on the gender role identity and perceptions about gender equity of pre-service early childhood teachers. Korean J Child Care Educ 54: 1-21, 2008.

7. Kim WS: A study on the effects of male sports leaders' ethical value view on their gender sensitivity and sexual assault attitude. KSSS 27: 55-67, 2018. https://doi.org/10.35159/kjss.2018.10.27.5.55

8. Lee HJ, Oh SY, Kim ES: A study on pre-service early childhood teachers' awareness of gender sensitivity. JKOAECE 23: 169-194, 2018. https://doi.org/10.20437/koaece23-2-08

9. Yoon SJ, Byun EK: Factors affecting gender equality consciousness of university students - the graduates of social welfare. JFMSE 29: 90-100, 2017. https://doi.org/10.13000/JFMSE.2017.29.1.90 
10. Kim YH, Lee SY: Developed Korean Gender Egalitarianism Scale (KGES-A) for youth. Korean Women's Development Institute, Seoul, pp.1-167, 2002.

11. Kwon OJ, Jang YE: The effects of exposure to parental violence on dating violence in college students: moderating effect of gender sensitivity. Locality Globality 43: 235-263, 2019.

https://doi.org/10.33071/ssricb.43.1.201904.235

12. Lee EH: Pre-service teachers' perception of gender equality consciousness and marriage values. TER 58: 267-278, 2019. https://doi.org/10.15812/ter.58.2.201906.267

13. Ah YA: The effects of gender role stereotypes of parents as perceived by adolescents on the gender sensitivity of adolescents and the moderating effect of human rights consciousness. J School Soc Work 51: 79-98, 2020. https://doi.org/10.20993/jSSW.51.4

14. Lee YR, Kim KM, Choi SE: Awareness levels and influencing factors of sexual harassment and gender egalitarianism among college students. J Korean Acad
Community Health Nurs 24: 40-50, 2013. https://doi.org/10.12799/jkachn.2013.24.1.40

15. Ryu KU, Jung JW: Research and analysis of present status of university general education in Korea. J Res Educ 28: 61-83, 2015.

16. Kim YS, Lee KY: Social work students' perceptions on Korean family law, attitudes on gender-roles, and implications for social work education. Korean J Fam Soc Work (9): 10-29, 2002.

17. Lee SH: Effects of education program on enhancing gender egalitarianism for college students. Korean J Educ Res 48: 107-133, 2010.

18. Lee KS: The effect of curriculum construction for the improvement of gender equality consciousness. J Law Relat Educ 5: 53-73, 2010. https://doi.org/10.29175/klrea.5.2.201012.53

19. Byun EK. Factors affecting gender equality consciousness of nursing college female students. AJMAHS 9: 661-671, 2019. https://doi.org/10.35873/ajmahs.2019.9.11.059 